\title{
Retreatment with Pegloticase after a Gap in Therapy in Patients with Gout: A Report of Four Cases
}

\author{
Allan H. Morton · Tony Hosey · Brian LaMoreaux
}

Received: March 26, 2018 / Published online: May 3, 2018

(C) The Author(s) 2018

\section{ABSTRACT}

Introduction: Pegloticase, a potent uricolytic biologic enzyme, has been shown to be an effective therapeutic option in patients with uncontrolled gout. However, there are limited data on clinical response after a gap in therapy and retreatment with pegloticase.

Case Series: This report describes four patients with chronic gout who were successfully managed with pegloticase and were retreated following a gap in therapy. Patient charts from a practice-based rheumatology clinic were retrospectively analyzed; four male patients, aged 70-75 years, with chronic gout and a more than 4-week gap in pegloticase therapy were reviewed. Before pegloticase treatment, patients had received allopurinol or febuxostat, but they

Enhanced digital features To view enhanced digital features for this article go to https://doi.org/10.6084/ m9.figshare.6148349.

\section{A. H. Morton}

Warren, MI, USA

A. H. Morton

Michigan State College of Osteopathic Medicine, East Lansing, MI, USA

T. Hosey · B. LaMoreaux ( $₫)$

Horizon Pharma USA, Inc., Lake Forest, IL, USA

e-mail: blamoreaux@horizonpharma.com continued exhibiting symptoms, including visible tophi and serum uric acid (SUA) levels of $5.2-10.2 \mathrm{mg} / \mathrm{dL}(309-607 \mu \mathrm{mol} / \mathrm{L})$, despite oral urate-lowering therapy. The first pegloticase treatment (8-mg infusion every 2 weeks) lasted 22-124 weeks. Pegloticase resolved tophi and improved SUA to below $1.5 \mathrm{mg} / \mathrm{dL}$ (less than $89 \mu \mathrm{mol} / \mathrm{L})$; however, patients discontinued pegloticase because of symptom resolution, poor adherence, or personal reasons. Following treatment gaps (12-156 weeks), symptoms and SUA levels increased and patients were retreated with pegloticase (4-147 weeks). In three of four patients, reinitiating pegloticase lowered SUA levels to below $1.0 \mathrm{mg} / \mathrm{dL}$ (less than $59 \mu \mathrm{mol} / \mathrm{L}$ ) and resolved symptoms. One patient experienced an infusion reaction and discontinued; no infusion reactions, gout flares, or adverse events occurred among the other three patients. Conclusion: Retreatment with pegloticase after a gap in therapy appears to be an effective and tolerated option in prior responders.

Funding: Horizon Pharma.

Keywords: Chronic gout; Pegloticase; Retreatment; Therapy gap

\section{INTRODUCTION}

Chronic gout is one of the most common forms of inflammatory arthritis in the USA [1]. Patients with uncontrolled gout often 
experience painful flares, resulting from elevated serum uric acid (SUA) levels and significant urate deposition [2]. Patients with gout often have numerous comorbid conditions requiring medical management, and many patients may require referral to a rheumatologist for gout management [3].

In clinical practice, many factors influence the resolution and remission of gout. A retrospective analysis linking medical records with patient questionnaire responses demonstrated that adherence to urate-lowering therapy (ULT) was associated with achieving SUA goals and symptomatic improvement [4]. However, patient adherence to ULT regimens is a particular challenge. One exploratory study found that some patients cited increased frequency of gout flares during initial treatment with allopurinol as the reason for treatment discontinuation [5]. Educating patients about the occurrence of flares at the onset of therapy is an important component of gout management but is not always sufficiently explained [6]. In addition, it often requires years of remaining adherent on ULT to resolve tophi and improve symptoms over time [7].

Some patients with chronic gout do not adequately respond to conventional ULT [8] and, therefore, have limited treatment options for lowering urate levels. Pegloticase (PEGylated recombinant mammalian uricase enzyme) is a potent uricolytic biologic enzyme therapy that rapidly converts existing uric acid into the more soluble and easily eliminated substrate allantoin [9]. Pegloticase is an effective therapeutic option in patients with uncontrolled gout and has been shown to decrease SUA levels within $24 \mathrm{~h}$ of the first infusion [10]. Treatment with pegloticase markedly decreases urate burden and promotes tophi clearance [10-13]. Notably, patients treated with pegloticase may experience a high gout flare rate during the first 3 months of therapy with a subsequent decline in the frequency of flares thereafter.

There are limited data on the clinical response to pegloticase following a gap in therapy. Two replicate, 6-month, randomized, placebo-controlled trials found that $42 \%$ of patients initially treated with pegloticase responded to therapy (defined as maintaining a plasma uric acid level less than $6.0 \mathrm{mg} / \mathrm{dL}$ [less than $357 \mu \mathrm{mol} / \mathrm{L}]$ for at least $80 \%$ of the treatment period) [10]. In a 2.5-year open-label extension of these studies, patients continued on pegloticase following a 12- to 223-day gap in therapy [14]. This open-label extension study demonstrated that, among patients who responded to pegloticase in the original trial, treatment continuation reduced SUA levels, tophi burden, and gout flares [13], with 29 of 34 responders $(85 \%)$ meeting criteria for gout remission [14, 15]. An additional analysis of pegloticase responders, with a gap of at least 28 days from the last dose in the pivotal trials to the first dose in the open-label extension, demonstrated that most of these patients maintained an SUA-lowering response to pegloticase upon retreatment [16]. However, it is unknown if patients in a real-world clinical setting can successfully reinitiate pegloticase therapy after a gap in treatment.

The present case series retrospectively evaluated the clinical outcomes of four patients with chronic gout who, after initial successful treatment with pegloticase, were retreated with pegloticase following a gap in therapy at a single rheumatology clinic. A secondary objective was to determine if retreatment with pegloticase after a gap in therapy was associated with any adverse outcomes.

Deidentified patient charts were retrospectively reviewed to identify patients with (1) chronic gout and (2) a prolonged (more than 4-week) lapse in pegloticase treatment. Before pegloticase initiation, the patients had ongoing symptoms of gout despite oral ULT. Demographics and disease characteristics of selected patients were recorded at baseline, including relevant comorbidities (diabetes mellitus, hypertension, coronary artery disease, hyperlipidemia, and chronic kidney disease), presence or absence of visible tophi, and duration of gout. Incidence of symptoms, adverse events (AEs), and laboratory profiles (serum creatinine [sCR], estimated glomerular filtration rate [eGFR], and SUA) were collected throughout the duration of therapy; reasons for treatment discontinuation were recorded when possible. Informed consent was obtained from all patients in the case series. 


\section{CASE SERIES}

\section{Baseline Characteristics and Disease History}

Four male patients, aged $70-75$ years, with chronic gout and a prolonged gap (more than 4 weeks) in pegloticase therapy were selected for review. A schematic overview of each patient's treatment and gaps in therapy is presented in Fig. 1.

At baseline evaluation, three patients (patients 1, 2, and 3) had comorbid coronary artery disease and two patients each had hypertension (patients 1 and 2) and chronic kidney disease (patients 2 and 3); all other comorbidities occurred in only one patient (Table 1). Before pegloticase treatment, patients were typically managed with allopurinol $300 \mathrm{mg}$ daily, with the exception of patient 3 who received allopurinol $300 \mathrm{mg}$ daily and then switched to febuxostat $80 \mathrm{mg}$ (Table 2). Patients had also received at least 6 months of prophylaxis with colchicine $0.6 \mathrm{mg}$ once or twice daily, depending on tolerance, and/or prednisone $5 \mathrm{mg}$ daily. All patients had ongoing manifestations of uncontrolled gout, despite oral ULT (Table 1). SUA levels before the initial course of pegloticase therapy ranged from 5.2 to $10.2 \mathrm{mg} / \mathrm{dL}$ (309-607 $\mu \mathrm{mol} / \mathrm{L})$; eGFR and sCR levels ranged from 33 to greater than $60 \mathrm{~mL} / \mathrm{min} / 1.73 \mathrm{~m}^{2}$ and 0.9 to $2.04 \mathrm{mg} / \mathrm{dL}(79.6-180.3 \mu \mathrm{mol} / \mathrm{L})$, respectively (Table 3; Fig. 1). For patient 4, there was a gap of approximately 1 year between his initial evaluation and treatment initiation, as pegloticase was not yet available; both values are shown in Table 3.

\section{Initial Treatment}

Consistent with standard of care, patients received pegloticase therapy (8-mg infusion every 2 weeks [Q2W]) after inadequate response to conventional oral ULT. To minimize the risk of anaphylaxis and infusion reactions (IRs), patients were pretreated with an antihistamine (diphenhydramine $\mathrm{HCl} 50 \mathrm{mg}$ per os) and intravenously administered (IV) hydrocortisone $200 \mathrm{mg}$ before pegloticase infusion. Patients also received concomitant prednisone $5 \mathrm{mg}$ daily throughout the duration of pegloticase therapy.

Initial pegloticase treatment lasted 22-124 weeks (Table 2). As patient 3 spent 6 months of the year out of state, he underwent periods of treatment by another physician; therefore, the exact number of doses he received is not available. Patient 4 had low adherence; an occasional 3-week and one 5-week lapse occurred between treatments. During pegloticase treatment, patients' SUA levels improved to below $1.5 \mathrm{mg} / \mathrm{dL}$ (less than $89 \mu \mathrm{mol} / \mathrm{L}$ ) (Fig. 2). eGFR and sCR levels were largely stable while on pegloticase therapy (Table 3). Two patients reported gout flares, one minor (patient 1) and one severe (patient 3, lasting 1 week). No patients experienced IRs or other AEs during the first pegloticase treatment (Table 4).

Two patients discontinued pegloticase because of physician's assessment following

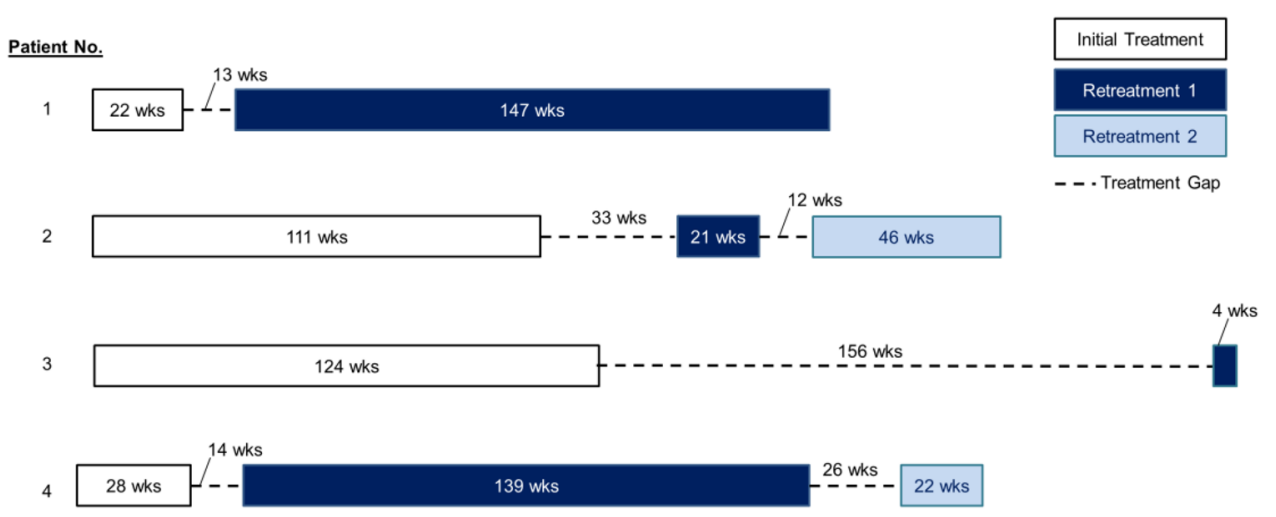

Fig. 1 Schematic of each patient's pegloticase treatment periods and gaps in pegloticase therapy. wks weeks 
Table 1 Demographics and baseline characteristics

\begin{tabular}{|c|c|c|c|c|}
\hline Parameter & Patient 1 & Patient 2 & Patient 3 & Patient 4 \\
\hline Age, years & 74 & 70 & 74 & 75 \\
\hline Sex & Male & Male & Male & Male \\
\hline Weight, kg & 140 & 76 & 112 & 85 \\
\hline $\begin{array}{l}\text { Disease } \\
\text { duration, } \\
\text { years }\end{array}$ & 30 & 40 & 15 & $>30$ \\
\hline Tophi status & Visible & Visible & Visible & Visible \\
\hline Comorbidities & $\begin{array}{l}\text { Hypertension, coronary artery } \\
\text { disease, diabetes mellitus, } \\
\text { obesity }\end{array}$ & $\begin{array}{l}\text { Hypertension, coronary } \\
\text { artery disease, chronic } \\
\text { kidney disease }\end{array}$ & $\begin{array}{l}\text { Coronary artery disease, } \\
\text { chronic kidney disease, } \\
\text { osteoarthritis }\end{array}$ & $\begin{array}{c}\text { Increased } \\
\text { lipids }\end{array}$ \\
\hline
\end{tabular}

resolution of symptoms (patients 2 and 3). Pegloticase was discontinued in patient 4 as a result of poor adherence with infusions and because gout-related symptoms had almost entirely resolved. Patient 1 discontinued pegloticase because of personal reasons (death of spouse) (Table 2).

\section{First Treatment Gap and Retreatment}

The length of the first treatment gap ranged broadly between patients, with 13 to 156 weeks elapsing between doses. During the treatment gap, patients 2 and 3 received febuxostat $80 \mathrm{mg}$ daily and patient 4 received allopurinol $500 \mathrm{mg}$ daily; therapy during the pegloticase treatment gap for patient 1 was not available (Table 2). Following the gap in therapy, patients experienced ongoing symptoms of gout. Patients 1 and 2 developed tophi, patients 2 and 4 experienced gout flares, and patient 3 had fatigue (Table 4). Elevated SUA levels were observed in all patients, ranging from 8.3 to $10.8 \mathrm{mg} / \mathrm{dL}$ (494-642 $\mu \mathrm{mol} / \mathrm{L}$ ) (Table 3; Fig. 2); for patients 1,3 , and 4 , eGFR ranged from 33 to $86 \mathrm{~mL} / \mathrm{min} /$ $1.73 \mathrm{~m}^{2}$ and sCR ranged from 0.9 to $2.0 \mathrm{mg} / \mathrm{dL}$ (79.6-176.8 $\mu \mathrm{mol} / \mathrm{L}$ ) (Table 3).

Patients were reinitiated on pegloticase therapy at $8 \mathrm{mg}$ Q2W concurrently with concomitant prednisone $5 \mathrm{mg}$ daily. As during the initial pegloticase treatment, patients were pretreated with oral diphenhydramine $\mathrm{HCl}$ $50 \mathrm{mg}$ and IV hydrocortisone $200 \mathrm{mg}$. Retreatment with pegloticase lasted from 4 to 147 weeks (Table 2).

The duration of retreatment for patient 3 lasted only 4 weeks because of an IR following the second dose of pegloticase. Before his first retreatment infusion, patient 3 had an SUA of $8.6 \mathrm{mg} / \mathrm{dL}(512 \mu \mathrm{mol} / \mathrm{L})$. Before his second dose, his SUA was $8.9 \mathrm{mg} / \mathrm{mL}(529 \mu \mathrm{mol} / \mathrm{L})$ (Table 3; Fig. 2). Despite preinfusion treatment with oral diphenhydramine $\mathrm{HCl} 50 \mathrm{mg}$ and IV hydrocortisone $200 \mathrm{mg}$, the resulting IR caused chest discomfort and decreased blood pressure, neither of which required an emergency department visit. The patient discontinued pegloticase treatment and continues to be treated with febuxostat $80 \mathrm{mg}$ daily. As of his last evaluation, the patient had an SUA of $4.6 \mathrm{mg} / \mathrm{dL}(274 \mu \mathrm{mol} /$ L) (Table 3).

With the exception of patient 3, SUA levels were low during pegloticase retreatment, and patients 1, 2, and 4 did not experience IRs, gout flares, or other AEs (Table 4; Fig. 2). Patient 1 discontinued pegloticase because of resolution of gout-related symptoms. He continues to be treated with allopurinol $300 \mathrm{mg}$ and lesinurad $200 \mathrm{mg}$ daily. Approximately 3 months after discontinuation of pegloticase, his SUA was $6.5 \mathrm{mg} / \mathrm{dL}(387 \mu \mathrm{mol} / \mathrm{L}) ;$ his eGFR and $\mathrm{sCR}$ levels were $62 \mathrm{~mL} / \mathrm{min} / 1.73 \mathrm{~m}^{2}$ and $1.21 \mathrm{mg} / \mathrm{dL}$ 
Table 2 Summary of pegloticase treatment

\begin{tabular}{|c|c|c|c|c|}
\hline & Patient 1 & Patient 2 & Patient 3 & Patient 4 \\
\hline \multicolumn{5}{|l|}{ Initial pegloticase treatment } \\
\hline Treatment before pegloticase & Allopurinol $300 \mathrm{mg}$ QD & $\begin{array}{l}\text { Allopurinol } \\
300 \mathrm{mg} \text { QD }\end{array}$ & $\begin{array}{l}\text { Allopurinol } 300 \mathrm{mg} \text { QD; } \\
\text { febuxostat } 80 \mathrm{mg} \text { QD }\end{array}$ & $\begin{array}{l}\text { Allopurinol } \\
300 \mathrm{mg} \\
\text { QD }\end{array}$ \\
\hline $\begin{array}{l}\text { Duration of initial pegloticase } \\
\text { treatment, weeks (doses) }\end{array}$ & $22(11)$ & $111(56)$ & $124^{\mathrm{a}}$ & $28(14)^{\mathrm{b}}$ \\
\hline Reason for discontinuation & Patient choice ${ }^{c}$ & $\begin{array}{l}\text { Resolution of } \\
\text { symptoms }\end{array}$ & Resolution of symptoms & $\begin{array}{l}\text { Patient } \\
\text { choice }^{\mathrm{d}}\end{array}$ \\
\hline \multicolumn{5}{|l|}{ First pegloticase retreatment } \\
\hline $\begin{array}{l}\text { Length of pegloticase } \\
\text { treatment gap, weeks }\end{array}$ & 13 & 33 & 156 & 14 \\
\hline $\begin{array}{l}\text { Treatment regimen during } \\
\text { pegloticase treatment gap }\end{array}$ & Unknown & $\begin{array}{l}\text { Febuxostat } \\
\qquad 80 \mathrm{mg} \text { QD }\end{array}$ & Febuxostat $80 \mathrm{mg}$ QD & $\begin{array}{l}\text { Allopurinol } \\
500 \mathrm{mg} \\
\text { QD }\end{array}$ \\
\hline $\begin{array}{l}\text { Duration of pegloticase } \\
\text { retreatment, weeks (doses) }\end{array}$ & $147(70)$ & $21(11)$ & $4(2)$ & $139(64)$ \\
\hline Reason for discontinuation & Resolution of symptoms & $\begin{array}{l}\text { Patient } \\
\text { choice }^{\mathrm{e}}\end{array}$ & Adverse event ${ }^{\mathrm{f}}$ & $\begin{array}{l}\text { Patient } \\
\text { choice }^{\mathrm{g}}\end{array}$ \\
\hline \multicolumn{5}{|l|}{ Second pegloticase retreatment } \\
\hline $\begin{array}{l}\text { Length of pegloticase } \\
\text { treatment gap, weeks }\end{array}$ & NA & 12 & NA & 26 \\
\hline $\begin{array}{l}\text { Treatment regimen during } \\
\text { pegloticase treatment gap }\end{array}$ & NA & $\begin{array}{l}\text { Febuxostat } \\
80 \mathrm{mg} \text { QD }\end{array}$ & NA & Unknown \\
\hline $\begin{array}{l}\text { Duration of pegloticase } \\
\text { retreatment, weeks (doses) }\end{array}$ & NA & $46(24)$ & NA & $22(9)$ \\
\hline Reason for discontinuation & NA & $\begin{array}{l}\text { Resolution of } \\
\text { symptoms }\end{array}$ & NA & $\begin{array}{l}\text { Resolution of } \\
\text { symptoms }\end{array}$ \\
\hline
\end{tabular}


Table 2 continued

\begin{tabular}{llccc}
\hline & Patient 1 & Patient 2 & Patient 3 & Patient 4 \\
\hline After final pegloticase treatment & & & & \\
Treatment regimen & Allopurinol & Allopurinol & Febuxostat & Allopurinol \\
& $300 \mathrm{mg}+$ lesinurad & $100 \mathrm{mg}$ & $80 \mathrm{mg}+$ lesinurad & $300 \mathrm{mg}$ \\
& $200 \mathrm{mg}$ QD & BID & $200 \mathrm{mg}$ QD & QD \\
\hline
\end{tabular}

$B I D$ twice daily, $N A$ not applicable, $Q D$ once daily

${ }^{a}$ Number of doses could not be confirmed as patient was treated at another office during two periods over the course of treatment

b Patient was frequently nonadherent to treatment plan; an occasional 3-week and one 5-week lapse occurred between doses

c Death of spouse

d Poor treatment adherence

e Insurance complications

${ }^{\mathrm{f}}$ Infusion reaction with chest discomfort and decreased blood pressure, neither of which required an emergency department visit

g Patient preferred to be treated during the summer and discontinued in the winter because of poor veins

(107.0 $\mu \mathrm{mol} / \mathrm{L})$, respectively (Table 3). Patients 2 and 4 discontinued pegloticase because of patient choice; patient 2 experienced insurance complications and patient 4 indicated that his veins were poor during the winter and chose to discontinue pegloticase treatment until the summer (Table 2).

\section{Second Treatment Gap and Retreatment}

Patients 2 and 4 reinitiated pegloticase after a second gap in therapy of 12 and 26 weeks, respectively. During the gap, patient 2 received febuxostat $80 \mathrm{mg}$ daily; treatment for patient 4 during this time was not available (Table 2). After the second gap in treatment, patient 2 developed tophi and patient 4 experienced a gout flare. SUA levels before retreatment for patients 2 and 4 were $2.4 \mathrm{mg} / \mathrm{dL}(143 \mu \mathrm{mol} / \mathrm{L})$ and $11.9 \mathrm{mg} / \mathrm{dL} \quad(708 \mu \mathrm{mol} / \mathrm{L})$, respectively (Table 3; Fig. 2).

Treatment with pegloticase resumed at $8 \mathrm{mg}$ Q2W with concomitant prednisone $5 \mathrm{mg}$ daily. As during previous pegloticase treatments, patients were pretreated with diphenhydramine $\mathrm{HCl} 50 \mathrm{mg}$ per os and hydrocortisone $200 \mathrm{mg}$ IV before pegloticase infusion. Retreatment lasted 46 weeks for patient 2 and 22 weeks for patient
4 (Table 2). During this time, neither patient experienced IRs, flares, or other AEs, and SUA levels for both patients were below $1.0 \mathrm{mg} / \mathrm{dL}$ (less than $59 \mu \mathrm{mol} / \mathrm{L}$ ) (Table 4; Fig. 2).

Both patients ultimately discontinued pegloticase treatment because of symptom resolution (Table 2). One month after his last infusion with pegloticase, patient 2 had an SUA of below $1.0 \mathrm{mg} / \mathrm{dL}$ (less than $59 \mu \mathrm{mol} / \mathrm{L}$ ); his eGFR and $\mathrm{sCr}$ levels were $42 \mathrm{~mL} / \mathrm{min} / 1.73 \mathrm{~m}^{2}$ and $1.70 \mathrm{mg} / \mathrm{dL}(150.3 \mu \mathrm{mol} / \mathrm{L})$, respectively, and he reported no gout flares (Tables 3, 4; Fig. 2). He continues to be treated with allopurinol $100 \mathrm{mg}$ twice daily (Table 2). Similarly, patient 4 reported no flares 4 months after his last treatment and he continues to be treated with allopurinol $300 \mathrm{mg}$ daily (Table 2).

\section{DISCUSSION}

Gout affects approximately 8.3 million people in the USA and is associated with poor quality of life, increased hospitalization, and morbidity $[1,2,17,18]$. While treatment options such as allopurinol and febuxostat are typically used as first-line therapies, some patients with gout do not adequately respond to traditional ULTs and continue to have elevated SUA, tophi, and gout 
Table 3 SUA and markers of kidney function over time

\begin{tabular}{lllll}
\hline Parameter & Patient 1 & Patient 2 & Patient 3 & Patient 4
\end{tabular}

Initial pegloticase treatment

Before pegloticase treatment

\begin{tabular}{|c|c|c|c|c|}
\hline SUA, mg/dL & 10.2 & 5.9 & 10.0 & $6.0^{\mathrm{a}}\left(5.2^{\mathrm{b}}\right.$ \\
\hline $\mathrm{eGFR}, \mathrm{mL} / \mathrm{min} / 1.73 \mathrm{~m}^{2}$ & 63 & 33 & 58.5 & $>60$ \\
\hline sCR, mg/dL & 1.15 & 2.04 & 1.3 & 0.9 \\
\hline
\end{tabular}

During pegloticase treatment

SUA, $\mathrm{mg} / \mathrm{dL}$
eGFR, $\mathrm{mL} / \mathrm{min} / 1.73 \mathrm{~m}^{2}$
sCR, $\mathrm{mg} / \mathrm{dL}$

$\begin{array}{llll}<0.5 & <1.5 & <0.5-1.6 & <0.5 \\ 54.6 & 39-49 & 53-58 & - \\ 1.3 & 1.50-1.76 & 1.3-1.4 & 0.9\end{array}$

End of first pegloticase treatment
SUA, mg/dL
eGFR, $\mathrm{mL} / \mathrm{min} / 1.73 \mathrm{~m}^{2}$
$\mathrm{sCR}, \mathrm{mg} / \mathrm{dL}$

$<0.5$

$<1.0$

$<0.5$

$<0.5$

First pegloticase retreatment

Before pegloticase retreatment

SUA, mg/dL
eGFR, $\mathrm{mL} / \mathrm{min} / 1.73 \mathrm{~m}^{2}$
sCR, $\mathrm{mg} / \mathrm{dL}$
During pegloticase retreatment

10.8

8.3

8.6

8.3

66.0

$-$

33

86

1.1

$-$

2.0

0.9

SUA, mg/dL

$<1.0$

$<1.0$

8.9

$<1.0$

eGFR, $\mathrm{mL} / \mathrm{min} / 1.73 \mathrm{~m}^{2}$

$59.5-72$

43-44

63-128

sCR, mg/dL

$1.07-1.2$

$1.65-1.68$

$0.5-1.20$

Follow-up
SUA, mg/dL
eGFR, $\mathrm{mL} / \mathrm{min} / 1.73 \mathrm{~m}^{2}$
sCR, mg/dL

$$
\begin{aligned}
& <1.0^{c}(6.5)^{d} \\
& 61^{c}(62)^{d} \\
& 1.23^{c}(1.21)^{d}
\end{aligned}
$$

NA

NA

NA

$-$

$-$

NA

$7.3^{e}(4.6)^{f}$

NA

$59.5^{\mathrm{e}}(49.7)^{\mathrm{f}}$

NA

Second pegloticase retreatment

Before pegloticase retreatment

SUA, mg/dL

eGFR, $\mathrm{mL} / \mathrm{min} / 1.73 \mathrm{~m}^{2}$

NA

$<1.0^{\mathrm{g}}(2.4)^{\mathrm{h}}$

$1.2^{\mathrm{e}}(1.4)^{\mathrm{f}}$

sCR, mg/dL

NA

39

NA

1.84

NA

$2.7^{\mathrm{i}}(11.9)^{\mathrm{j}}$

During pegloticase retreatment

SUA, mg/dL

NA

$<1.0$

NA

$<1.0$ 
Table 3 continued

\begin{tabular}{lllll}
\hline Parameter & Patient 1 & Patient 2 & Patient 3 & Patient 4 \\
\hline eGFR, $\mathrm{mL} / \mathrm{min} / 1.73 \mathrm{~m}^{2}$ & $\mathrm{NA}$ & $43-52$ & $\mathrm{NA}$ & - \\
$\mathrm{sCR}, \mathrm{mg} / \mathrm{dL}$ & $\mathrm{NA}$ & $1.43-1.67$ & $\mathrm{NA}$ & - \\
Follow-up & & & & \\
$\mathrm{SUA}, \mathrm{mg} / \mathrm{dL}$ & $\mathrm{NA}$ & $<1.0^{\mathrm{k}}$ & $\mathrm{NA}$ & - \\
eGFR, $\mathrm{mL} / \mathrm{min} / 1.73 \mathrm{~m}^{2}$ & $\mathrm{NA}$ & 42 & $\mathrm{NA}$ & - \\
$\mathrm{sCR}, \mathrm{mg} / \mathrm{dL}$ & $\mathrm{NA}$ & 1.70 & $\mathrm{NA}$ & - \\
\hline
\end{tabular}

To convert $\mathrm{mg} / \mathrm{dL}$ to $\mu \mathrm{mol} / \mathrm{L}$ for SUA, multiply by 59.485 . To convert $\mathrm{mg} / \mathrm{dL}$ to $\mu \mathrm{mol} / \mathrm{L}$ for $\mathrm{sCR}$, multiply by 88.4 - Indicates not available, $e G F R$ estimated glomerular filtration rate, $N A$ not applicable, $s C R$ serum creatinine, $S U A$ serum uric acid

a Taken approximately 1 year before initiating therapy

b Taken approximately 6 months before initiating therapy

c Taken approximately 1 week after the last infusion

d Taken approximately 13 weeks after the last infusion

e Taken approximately 6 weeks after the last infusion

f Taken approximately 15 weeks after the last infusion

g Taken approximately 11 weeks after the last infusion

h Taken approximately 12 weeks after the last infusion

i Taken approximately 10 weeks after the last infusion

j Taken approximately 24 weeks after the last infusion

k Taken approximately 4 weeks after the last infusion

flares, leaving them with few treatment options $[17,19,20]$. Pegloticase has been shown to decrease SUA levels and tophi burden and increase health-related quality of life in patients with an inadequate response to other therapies [8-10, 13, 14, 16].

A particular challenge in the treatment of gout is patient adherence. In this rheumatology practice, the treating physician is a solo practitioner with over 35 years in practice; gout therapy at his practice involves patient education to improve adherence to the treatment regimen. A number of factors can lead to poor adherence, including AEs at treatment onset, concerns about future AEs, or financial difficulties related to the cost of therapy [21]. However, evidence suggests that patient education concerning the temporary increase in gout flares at the onset of ULT is lacking and may be a contributing factor to low compliance and adherence [6, 22]. Importantly, patients with poor adherence are less likely to achieve or maintain an SUA level of below $6.0 \mathrm{mg} / \mathrm{dL}$ (less than $357 \mu \mathrm{mol} / \mathrm{L})$ compared with adherent patients [23, 24].

Pegloticase is an option for patients with uncontrolled gout who cannot take traditional oral ULT or in whom these medications are contraindicated. However, the dosing regimen of pegloticase requires infusions Q2W, with preinfusion SUA checks before each infusion. For a variety of reasons, patients such as the four cases presented here missed doses and experienced gaps during their pegloticase treatment course.

As patients may reinitiate pegloticase treatment after missing doses or upon re-emergence of their gout signs and symptoms, it is important to understand how a temporary gap may affect subsequent retreatment. In a subanalysis 

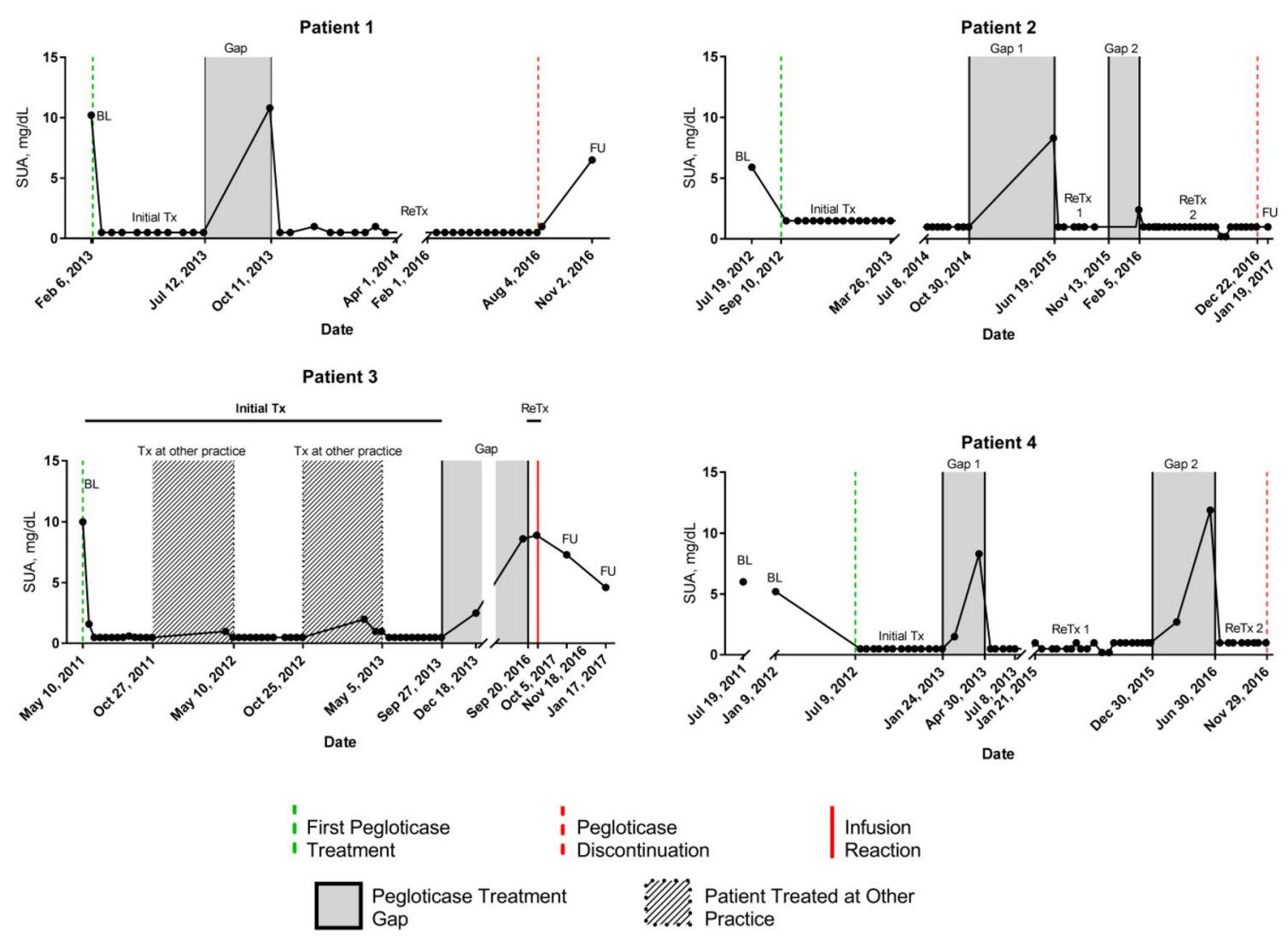

Fig. 2 SUA levels over time during treatment with pegloticase, pegloticase treatment gaps, and retreattreatment. To convert $\mathrm{mg} / \mathrm{dL}$ to $\mu \mathrm{mol} / \mathrm{L}$ for $S U A$, multiply by 59.485 ment(s) with pegloticase in each patient. BL baseline, FU follow-up, ReTx retreatment, SUA serum uric acid, Tx

Table 4 AEs and disease symptoms during pegloticase therapy

\begin{tabular}{lll}
\hline Parameter & Patient 1 & Patient 2
\end{tabular}

Patient 3

Patient 4

Initial pegloticase treatment

AEs during initial treatment

Mild flare None

Severe flare (lasting 1 week) None

First pegloticase retreatment

Symptoms after gap in therapy

AEs during retreatment

Tophi

Tophi and gout flares

Fatigue

Gout flares

Second pegloticase retreatment

Symptoms after gap in therapy

NA

Tophi

NA

Gout flare

AEs during retreatment

NA

None

NA

None

$A E s$ adverse events, $N A$ not applicable

${ }^{a}$ Infusion reaction with chest discomfort and decreased blood pressure, neither of which required an emergency department visit 
of two randomized clinical trials, most pegloticase responders with at least a 28-day gap in therapy $(n=10 / 14$ [71\%]) maintained an SUA below $6.0 \mathrm{mg} / \mathrm{dL}$ (less than $357 \mu \mathrm{mol} / \mathrm{L}$ ) upon retreatment; furthermore, logistic regression indicated that the length of the treatment gap did not correlate with any urate-lowering effects upon reinitiation [16]. Therefore, in the clinical trial setting, it appears that discontinuation of pegloticase did not diminish its effectiveness or raise any new safety signals upon retreatment.

In this case series, the efficacy of pegloticase in four patients with varying gaps in therapy (12-156 weeks) was retrospectively evaluated in routine clinical practice. The responder rate to retreatment was similar to that observed in clinical trials; in three of four patients (75\%) who reinitiated therapy, pegloticase effectively reduced SUA levels and resolved tophi with no gout flares, IRs, or other AEs. One patient experienced an IR, which was resolved without emergency medical intervention and led to discontinuation of pegloticase retreatment. Renal function remained relatively stable for each patient during treatment with pegloticase. Patients also self-reported improvements in quality of life to the physician while receiving pegloticase therapy.

Without application of the preinfusion SUA stopping rules, which suggest ceasing treatment in the event of an SUA increase (at least $6.0 \mathrm{mg} /$ $\mathrm{dL}$ [at least $357 \mu \mathrm{mol} / \mathrm{L}]$ ) following pegloticase infusion, $26 \%$ of patients in clinical trials experienced IRs [25]. However, when the SUA stopping rule was applied, this incidence dropped by nearly one-half, to $14 \%$ of patients. IRs from pegloticase treatment commonly include chest discomfort, flushing, and dyspnea during or immediately following an infusion. The development of high titers of anti-pegloticase antibodies, which are believed to interfere with enzymatic function of pegloticase, can precipitate an IR. Therefore, while on pegloticase therapy, an increase in preinfusion SUA can reflect a decrease in pegloticase efficacy and can be used as a biomarker for the risk stratification of an IR $[25,26]$. In the case of the IR experienced by patient 3 , his elevated SUA before his last infusion $(\mathrm{SUA}=8.9 \mathrm{mg} / \mathrm{dL} \quad[529 \mu \mathrm{mol} / \mathrm{L}])$ would have ideally deterred the subsequent infusion, potentially preventing the IR that occurred. While anti-pegloticase antibodies were not measured in these patients (aged 70-75 years), a previous analysis of two clinical trials found that low titers of antibodies and older age were both associated with higher response rates to pegloticase, suggesting that age may influence the development of anti-pegloticase antibodies and treatment responsiveness [26]. Further study of the effect of repeated treatment on the immunogenicity of pegloticase is needed but logistically challenging.

This report describes the pegloticase retreatment experience of one single-practitioner rheumatology clinic and, as such, several limitations may be considered. There are similarities between the cases, although all data points are purely observational. Given the indication and best-practice use with pegloticase as a Q2W medication, a controlled study on retreatment with pegloticase after a gap in therapy is unlikely to occur.

\section{CONCLUSIONS}

In three of the four cases presented here, retreatment with pegloticase in prior responders was as effective and safe as during initial treatment. The goal of this publication was to provide a real-world look at the retreatment experience with pegloticase following a gap in therapy at one rheumatology clinic. When treating patients with uncontrolled gout with pegloticase who were SUA responders but discontinued therapy for any reason, it appears that retreatment may be an effective and tolerable therapeutic option.

\section{ACKNOWLEDGEMENTS}

Funding. Sponsorship for development of this article and article processing charges was funded by Horizon Pharma USA, Inc. All authors had full access to all of the data in this study and take complete responsibility for the integrity of the data and accuracy of the data analysis. 
Medical Writing and/or Editorial Assistance. Medical writing support was provided by Meghan Sullivan, PhD, CMPP, and Amanda Sheldon, PhD, CMPP, of inScience Communications, Springer Healthcare (New York, NY, USA), which was funded by Horizon Pharma USA, Inc.

Authorship. All named authors meet the International Committee of Medical Journal Editors (ICMJE) criteria for authorship for this article, take responsibility for the integrity of the work as a whole, and have given their approval for this version to be published.

Disclosures. Allan H. Morton serves as a consultant for Amgen, Horizon, Ironwood, Pfizer, and Sanofi Regeneron and is a speaker for AbbVie, Amgen, Celgene, Horizon, Ironwood, Janssen, Novartis, and Pfizer. Tony Hosey is an employee of and owns stock in Horizon Pharma. Brian LaMoreaux is an employee of and owns stock in Horizon Pharma.

Compliance with Ethics Guidelines. Informed consent was obtained from all patients in the case series. We thank the participants of the study.

Data Availability. The data sets analyzed during the current study are not publicly available, as they contain protected health information, but are available from the corresponding author on reasonable request.

Open Access. This article is distributed under the terms of the Creative Commons Attribution-NonCommercial 4.0 International License (http://creativecommons.org/licenses/ by-nc/4.0/), which permits any noncommercial use, distribution, and reproduction in any medium, provided you give appropriate credit to the original author(s) and the source, provide a link to the Creative Commons license, and indicate if changes were made.

\section{REFERENCES}

1. Zhu Y, Pandya BJ, Choi HK. Prevalence of gout and hyperuricemia in the US general population: the
National Health and Nutrition Examination Survey 2007-2008. Arthritis Rheumatol. 2011;63:3136-41.

2. Khanna PP, Nuki G, Bardin T, et al. Tophi and frequent gout flares are associated with impairments to quality of life, productivity, and increased healthcare resource use: results from a cross-sectional survey. Health Qual Life Outcomes. 2012;10:117.

3. Karis E, Crittenden DB, Pillinger MH. Hyperuricemia, gout, and related comorbidities: cause and effect on a two-way street. South Med J. 2014;107:235-41.

4. Coburn BW, Bendlin KA, Sayles H, Meza J, Russell CL, Mikuls TR. Allopurinol medication adherence as a mediator of optimal outcomes in gout management. J Clin Rheumatol. 2017;23:317-23.

5. Harrold LR, Mazor KM, Velten S, Ockene IS, Yood RA. Patients and providers view gout differently: a qualitative study. Chronic Illn. 2010;6:263-71.

6. Robinson PC, Schumacher HR Jr. A qualitative and quantitative analysis of the characteristics of gout patient education resources. Clin Rheumatol. 2013;32:771-8.

7. Perez-Ruiz F, Atxotegi J, Hernando I, Calabozo M, Nolla JM. Using serum urate levels to determine the period free of gouty symptoms after withdrawal of long-term urate-lowering therapy: a prospective study. Arthritis Rheumatol. 2006;55:786-90.

8. Strand V, Khanna D, Singh JA, Forsythe A, Edwards NL. Improved health-related quality of life and physical function in patients with refractory chronic gout following treatment with pegloticase: evidence from phase III randomized controlled trials. J Rheumatol. 2012;39:1450-7.

9. Krystexxa $^{\circledR}$ (pegloticase injection), for intravenous infusion: US prescribing information. Lake Forest, IL: Horizon Pharma USA, Inc.; 2016.

10. Sundy JS, Baraf HS, Yood RA, et al. Efficacy and tolerability of pegloticase for the treatment of chronic gout in patients refractory to conventional treatment: two randomized controlled trials. JAMA. 2011;306:711-20.

11. Sherman MR, Saifer MG, Perez-Ruiz F. PEG-uricase in the management of treatment-resistant gout and hyperuricemia. Adv Drug Deliv Rev. 2008;60:59-68.

12. Sundy JS, Becker MA, Baraf HS, et al. Reduction of plasma urate levels following treatment with multiple doses of pegloticase (polyethylene glycolconjugated uricase) in patients with treatmentfailure gout: results of a phase II randomized study. Arthritis Rheumatol. 2008;58:2882-91. 
13. Baraf HS, Becker MA, Gutierrez-Urena SR, et al. Tophus burden reduction with pegloticase: results from phase 3 randomized trials and open-label extension in patients with chronic gout refractory to conventional therapy. Arthritis Res Ther. 2013;15:R137.

14. Becker MA, Baraf HS, Yood RA, et al. Long-term safety of pegloticase in chronic gout refractory to conventional treatment. Ann Rheum Dis. 2013;72:1469-74.

15. Schlesinger N, Khanna P, Yeo A, Lipsky PE. Evidence-based development of criteria for complete response in patients with chronic refractory gout. Arthritis Rheumatol. 2017;69:2070.

16. Baraf H, Morton A, LaMoreaux B, Kent J. Pegloticase re-treatment after a gap in therapy: data from two phase III trials nad an open-label extension study. Ann Rheum Dis. 2017;76:1360.

17. Khanna D, Fitzgerald JD, Khanna PP, et al. 2012 American College of Rheumatology guidelines for management of gout. Part 1: systematic nonpharmacologic and pharmacologic therapeutic approaches to hyperuricemia. Arthritis Care Res. 2012;64:1431-46.

18. Sattui SE, Gaffo AL. Treatment of hyperuricemia in gout: current therapeutic options, latest developments and clinical implications. Ther Adv Musculoskelet Dis. 2016;8:145-59.

19. Brook RA, Forsythe A, Smeeding JE, Lawrence Edwards N. Chronic gout: epidemiology, disease progression, treatment and disease burden. Curr Med Res Opin. 2010;26:2813-21.
20. Khanna D, Khanna PP, Fitzgerald JD, et al. 2012 American College of Rheumatology guidelines for management of gout. Part 2: therapy and antiinflammatory prophylaxis of acute gouty arthritis. Arthritis Care Res. 2012;64:1447-61.

21. Aung T, Myung G, FitzGerald JD. Treatment approaches and adherence to urate-lowering therapy for patients with gout. Patient Prefer Adherence. 2017;11:795-800.

22. Sarawate CA, Brewer KK, Yang W, et al. Gout medication treatment patterns and adherence to standards of care from a managed care perspective. Mayo Clin Proc. 2006;81:925-34.

23. Halpern R, Mody RR, Fuldeore MJ, Patel PA, Mikuls TR. Impact of noncompliance with urate-lowering drug on serum urate and gout-related healthcare costs: administrative claims analysis. Curr Med Res Opin. 2009;25:1711-9.

24. Rashid N, Coburn BW, Wu YL, et al. Modifiable factors associated with allopurinol adherence and outcomes among patients with gout in an integrated healthcare system. J Rheumatol. 2015;42:504-12.

25. Baraf HS, Yood RA, Ottery FD, Sundy JS, Becker MA. Infusion-related reactions with pegloticase, a recombinant uricase for the treatment of chronic gout refractory to conventional therapy. J Clin Rheumatol. 2014;20:427-32.

26. Lipsky PE, Calabrese LH, Kavanaugh A, et al. Pegloticase immunogenicity: the relationship between efficacy and antibody development in patients treated for refractory chronic gout. Arthritis Res Ther. 2014;16:R60. 